\title{
Performance Analysis of An Experimental Micro Flexible Manufacturing System (FMS)
}

\author{
Prof. Dr. Şahin YILDIRIM \\ Erciyes University, Faculty of Engineering, \\ Mechatronic Engineering Department, \\ Kayseri, 38039, Turkey \\ sahiny@erciyes.edu.tr
}

\author{
Osman YÜCEL \\ Erciyes University, Faculty of Engineering, \\ Mechatronic Engineering Department, \\ Kayseri, 38039, Turkey \\ yucelosman@hotmail.com
}

\begin{abstract}
Due to advanced technology, it is very important the performance of FMS for sensivity, production quality, repeatability and energy consumptions. Flexible manufacturing systems (FMSs) are the most automated and technologically sophisticated of the machine cell types used to implement cellular manufacturing. An FMS usually has multiple automated stations and is capable of variable routings among stations, while its flexibility allows it to operate as a mixed model system. The FMS concept integrates many of the advanced technologies that we met in previous units, including flexible automation, CNC machines, distributed computer control, and automated material handling and storage.
\end{abstract}

In this experimental investigation, vibration and accelerations analysis of an experimental FMS with 5 degrees of freedom robot manipulator are presented. Firstly, experimental measurement of accelerations and vibrations are trained with a vibration measurement system and sensors. However, the process of production of part is a cycle of exact production time.

Keywords-Measurement, FMS, Robot manipülatör, Accelerations, Vibrations, Prediction.

\section{INTRODUCTION}

In industrial applications, Flexible Manufacturing Systems (FMSs) are the most important, automated and technologically sophisticated of the machine cell types used to implement cellular manufacturing with advanced technology. A micro FMS usually has multiple automated stations and is capable of variable routings among stations, while its flexibility allows it to operate as a mixed model system. The FMS concept integrates many of the advanced technologies that we met in previous units, including flexible automation, CNC machines, distributed computer control, and automated material handling and storage.

Flexible manufacturing systems (FMS's) have been an important breakthrough towards fully automated and computer-integrated production in production applications. A FMS is essentially a computer-controlled production system, which brings together different standalone machines and control equipment capable of processing a variety of part types or jobs. FMS differs from the conventional systems in terms of flexibility in the flow of materials from one tool to another and performing the operations as per the required sequence. Each part can follow a variable route through the system. In a nut shell, flexibility in material handling, in combination with multipurpose tools, makes it possible for a flexible manufacturing system to process a great diversity of parts. (Cardinali, 1995). Some of the advantages of FMS include: improved capital/equipment utilization, reduced work in progress and set up, substantially reduced throughput times/lead times, reduced inventory and smaller batches, and reduced manpower.

Several authors had studied design, planning, scheduling, and control of FMS and proposed various techniques to model and analyze FMS performance (Abdulziz et al., 2012). They embraced various problems such asselection of best dispatching, scheduling, routing and control rules, determination of optimal number of machines, optimal number of AGVs and/or buffers/pallets, and optimization of a specific product machining parameter (such as full load speed of sheet metal piler) (Basnet and Mize, 1994, Chan et al., 2002). Diverse factors such as AGVs availability, variable machining time, system layout, routing and sequencing flexibility and part mix were considered (Solot and Vliet, 1994, Chan and Chan, 2004). Performance criteria such as make-span (time to complete all jobs), tardiness (the difference between completion times and due dates), total processing time, flow time, production rate, cost and machine utilization were assessed (Azimi et al., 2010, Joseph and Sridharan, 2011, Kumar and Sridharan, 2011, Singholi et al., 2010). In addition,various approaches and models were usedin FMS research such as mathematical programming (Abou Gamila et al., 2000), multi-criteria decision making (Karsak, 2000), dynamic programming (Ecker and Gupta, 2005), goal programming (Chan and Swarnkar, 2006), petri-net (Hamid, 2010), linear and nonlinear programming (Chan and Chan, 2004) and investment model (Bruce and Albert, 1999). Today, FMS is complex due to variation in layout, MHS configuration, and stochastic parts inter-arrival and processing times, which makes FMS problems multidimensional in nature (Saygin et al., 2001). It might be difficult to use analytical approaches to model a complex manufacturing environments such FMS with their entire operating and physical characteristics. Analytical modeling will befurther complicated to use when dynamic operating environments and control time aspect are considered (Chan et al., 2007). Furthermore, the analytical modeling approaches are usually based on simplifying assumptions for the system under study 
and specific to individual manufacturing enterprises and processes (Chan et al., 2002). These assumptions may not provide an actual image of FMS performance and may not be representative of real-world cases (Chan et al., 2007). On the other hand, simulation-based approaches have been used for modeling and analyzing complex manufacturing systems, since they can model the variables which are mathematically complicated, and represent more realistic environments (Singholi et al., 2010). It also can deal with stochastic environments, for which analytical models such as mathematical programming have been inferior without major simplifications (Chan and Chan, 2004). McLean and Kibira (2002) concluded that simulation could be the best decisionmaking aid during design, analyze and improvement of manufacturing systems.

Several authors used simulation to model and analyze FMS performance. Yifei et al. (2010) discussed AGV fleet size determination in FMS using estimation and simulation.They estimated the AGV fleet size mathematically and applied the results in a simulation model of AGVs for further evaluation. Studying scheduling problems, Shafiq et al. (2010) proposed a framework for studying the effect of scheduling, system configuration, buffer capacity, routing flexibility (manufacturing flexibility), number of pallets, volume of parts, dispatching and sequencing rules (scheduling rules) on FMS performance (i.e., make-span time, cost, machine utilization and queue waiting time). They concluded that the make-span and queue waiting time decrease while machine utilization and production cost increase with the increase in routing flexibility level. Discussing performance analysis problems, Singholi et al. (2010) conducted a real FMS case study to analyze its existing performance such as maximum production rate, make-span and overall utilization, determined by a quantitative modeling, and prepared an improvement plan to be compared with the existing using simulation modeling. The modification includes adding resources (i.e., sizing the system) and implementing new layout. The results showed that the proposed FMS has increased of the number of servers, maximum production rate and overall utilization of resources. Meanwhile, Abou-Ali and Shouman (2004) discussed a study of the effect of 12 dynamic and static dispatching strategies on dynamically planned and unplanned FMS consisting of eight machines, storage buffer areas, receiving area, and three robots and pallets. The authors showed that an overall improvement could be achieved for dynamic dispatching than that rendered by static dispatching. An application of reconfigurable hardware technology in the development and implementation of building automation systems has been investigated by Géza. Csaba and Hideki (2014). On the other hand, an artificial Immune System Implementation upon Embryonic Machine for Hardware Fault-tolerant Industrial Control Applications has been studied and improved by Géza, Csaba, and Chindris (2010). The use of a proposed recurrent hybrid neural network to control of walking robot with four legs has been investigated by Yildirim (2008). In his investigation, a neural networks based control system has been utilized to the control of four-legged walking robot.

This paper is an attempt to make a comprehensive investigation of Flexible Manufacturing Systems covering their essential and crucial aspects. The facts related to the flexibility issues of FMS are discussed and outlined in section 2. Further on, light in thrown on the key issues, the decision variables and performance measures in FMS. Experimental work discussing the implementation of micro FMS are also presented in setion 3. Robot manipülatör theory is described in section 4 . The paper is concluded in the last section of 5 with discussion.

\section{FLEXIBLE MANUFACTURING SYSTEMS (FMS)}

As defined and outlined above section, the FMS is a highly automated group technology machine cell, consisting of a group of processing workstations often computer numerical control machine tools - that are interconnected by an automated material handling and storage system, and controlled by a distributed computer system. Flexibility is an important part of this definition. As we shall see below, where we discuss it in more detail, flexibility can have different interpretations; but it generally refers to the system's responsiveness to changing demand patterns, so that the mix of part styles in the system, and the production volumes that can be met, can be adjusted rapidly to meet changing requirements.

Another keyword in the definition is group technology, which was discussed in the introduction. In reality no FMS can be perfectly flexible, meaning that there are limits to the range of parts or products that can be made on the system. Consequently an FMS must be designed to produce parts (or products) within a defined range of styles, sizes, and processes - that is, the FMS will have the capability of producing a single part family, or a limited range of part families. It cannot do both.

These capabilities are expressed in various ways in the micro FMS, which can best be seen from an example such as is provided in Figure 1. This figure depicts an automated manufacturing cell with two machine tools and robot manipulator. The question arising from this figure is: is it a flexible cell? To be considered flexible there are four reasonable tests that can be applied to the system to determine its level of flexibility.

Flexible manufacturing system (FMS) consists of four or more processing stations connected mechanically by a common parts handling system and electronically by a distributed computer system (as in Figure 2). FMS is larger than the flexible manufacturing cell, not only in the number of workstations it may contain, but also in the number of supporting stations in the system, such as part/pallet washing stations, co-ordinate measuring machines, storage stations and so on. Computer control is also more sophisticated; it includes functions not found in the flexible manufacturing cell such as diagnostics and tool monitoring. The FMS satisfies all four flexibility tests.

Furthermore, a comparison of the three FMS types is illustrated in Figure 3, where the number of machines is plotted against metrics of investment, production rate and annual volume.

\section{REPRESENTATION OF MATERIAL HANDLING ROBOT MANIPULATOR OF FMS}

The robot manipulator described is a six-axis industrial robot with jointed-arm kinematics for all point-to-point and continuous-path controlled tasks. Its main areas of application are: (i) Handling, (ii) Assembly, (iii) Application of adhesives, sealants and preservatives (iv)Machining. This robot has five degrees of freedom. It is employed to analyze the vibration parameters of joints as shown in Figure 4 and Table 1 as micro FMS. The robot manipulator's joints are driven by electromechanical, with transistor controlled AC servo motors. Maximum speed of robot manipulator's end-effector is 
approximately $2100 \mathrm{~mm} / \mathrm{sec}$. The positioning repetition accuracy of the robot manipulator is $\pm 0.1 \mathrm{~mm}$. The axis properties for the investigated material handling robot manipulator are given in Table 2. The dynamics of robot manipulator with five rigid links can be written as;

$$
M(q(t)) \ddot{q}(t)+V_{m}(q(t), \dot{q}(t)) \dot{q}(t)+F(\dot{q}(t))+G(q(t))+\tau_{d}(t)=\tau(t)
$$

where $M(q(t))$ is then nxn inertia matrix of the robot manipulator, $V_{m}(q(t), \dot{q}(t)$ is the nx1 vector of centrifugal and Coriolis terms, $F(\dot{q}(t))$ is the nxn friction term, $G(q(t))$ is $\mathrm{nx} 1$ the vector of gravity terms and $\tau_{d}(t) \mathrm{nx} 1$ represents disturbances $(\mathrm{n}=5)$. The control input vector $\tau(t)$ has $\mathrm{nx} 1$ components of torque for revolute joints and force for prismatic joints. It is often convenient to write the robot manipulator dynamics as;

$$
\mathrm{M}(\theta(\tau)) \ddot{\theta}(\tau)+\mathrm{N}(\theta(\tau), \dot{\theta}(\tau))+\tau_{\delta}(\tau)=\tau(\tau)
$$

where

$$
N(q(t), \dot{q}(t)) \equiv V_{m}(q(t), \dot{q}(t)) \dot{q}(t)+F(\dot{q}(t))+G(q(t))
$$

represents a vector of the nonlinear terms. As depicted from Equation (3), the joints of robot manipulator are affected by friction terms. These terms can be described;

$$
F(\dot{q}(t))=F_{v}(t) \dot{q}(t)+F_{d}((\dot{q}(t))
$$

with $F_{v}(t)$ a diagonal matrix of constant coefficients representing the viscous friction and $F_{d}((\dot{q}(t))$ is a vector with entries like $K_{d n} \operatorname{sgn}\left(\dot{q}_{n}\right)$ with $\operatorname{sgn}\left(\dot{q}_{n}\right)$ the signum function and Kdn the coefficients of dynamic friction of each joint of robot manipulator.

\section{A. Controller Structure of the material handling robot manipulator}

The material handling robot manipulator controller has some properties as follows: Performance and expansion over and above the basic control functions, open system for future developments and ease of integration in any network, recognized standards, special functions for increased productivity, built-in safety features for greater availability, input functions for faster programming, ready-made software packages and real-time capable simulations and offline programs with absolutely accurate data. The material handling robot manipulator controller consists of four components and FMS is also described in Figure 5. These are can be described in the following;

- Control PC: The PC performs all the functions of the robot controller. The control PC includes the following components: Motherboard with interfaces, processor and main memory, hard drive, floppy disk drive, CD-ROM drive, MFC3, KVGA, DSE-IBS-C33, batteries and bus cards.

- Teach pendant: The teach pendant has all the functions required for operating and programming the robot system.

- Safety logic: The safety logic is a dual-channel computer aided safety system. It permanently monitors all connected safety-relevant components. In the event of a fault or interruption in the safety circuit, the power supply to the drives is shut off, thus bringing the robot system to a standstill.

\section{- $\quad$ Power unit}

The hardware of the system is a single processor basis. With a latest generation high-performance processor for two parallel operates systems.

\section{EXPERIMENTAL ANALYSES}

Experimental investigation on material handling and feeding robot manipulator's performence analyse was carried out with two types of materials handling and feeding to micro FMS. The presentation of two types of materials are shown in Figure 6. As can be seen from figures, polymid plastic material has hight of $58 \mathrm{~mm}, 40 \mathrm{~mm}$ diameter and 83 gram mass. However, metal material has hight of $58 \mathrm{~mm}, 40 \mathrm{~mm}$ diameter and 205 gram mass. Firstly is experimental measurements on robot manipulator's joints. The process consisted of 1 intelligent data acquisition (IDA), 4 accelerometers, a microphone and PC the experimental setup used to collect the joint accelerations for the case of the four different running speeds processing of material handling robot manipulator (see Fig.7). On the second stage, the measured experimental accelerations values were used as desired signals for analysing and finding exact speed for two types of different materail processing such as plastic and metal.

Experimental results are shown in Figs. 8-15, respectively. By considering the maximum speed $2100 \mathrm{~mm} / \mathrm{sec}$ of $10 \%$ running speed, the experimental noise variation of the material handling robot manipulator is given in Fig. 8. Figure shows the results of vibration variations of four joins of robot manipülatör. It can be seen from the figure, joint 1's vibrations are 0,5 and $0,01 \mathrm{~mm} / \mathrm{sec} 2$. The results of experimental approach are represented in Figure 9. These graph results sho the case of plastic materila feding and processing for micro FMS. From the figures, joint 1 has random vibration disturbances. The case of increasing the maxmum speed of joints from $10 \%$ to $\% 50$ are shown in Figure 10. with metal material handling and feedinf fort he system. From figure, joint 2 has random vivration disturbances until $400 \mathrm{~Hz}$ frequency.

Figure 11 presents the acceleration results of the desired approach and experimental of the material handling robot manipulator joints with reduced $\% 50$ maximum speeds of the joints for plastic materail handling and feding to micro FMS.

It is clear to see from graphs, that there are large vibration disturbances for joint 1 of robot manipülatör for the case of $\% 50$ reduced speed of robot manipulator's joints. In particular, these disturbances the peak values at the frequency of $400-450 \mathrm{~Hz}$ for the experimental measurements.

The other type of anayse of material handling robot manipülatör is the case of $\% 70$ decreased maximum speed. Metal material structure is used to predict acceleration variations of the robot manipulator joints with $\% 70$ increased running speed and the results are shown in Figs. 12 for 4 measuring points of joints. As can be seen in relevant figures, the joint 3 has large disturbances rather than other joints values.

Furthermore, Fig.13 shows noise variation of the robot manipulator with plastic material handling for the case of $\% 70$ reduced running speed.

Figure 14 indicates the results of experimental approach for acceleration variations of the robot manipulator joints with a metal material on end-effector and maximum running speed. As pointed out from the figures, the results of joint 2 
approach give poor performance during materila handling. Again, the same structure is used to predict acceleration of the handling robot manipulator joints with plastic material and maximum running speed (see Figs. 15). Moreover, there is big disturbances for joint 1 .

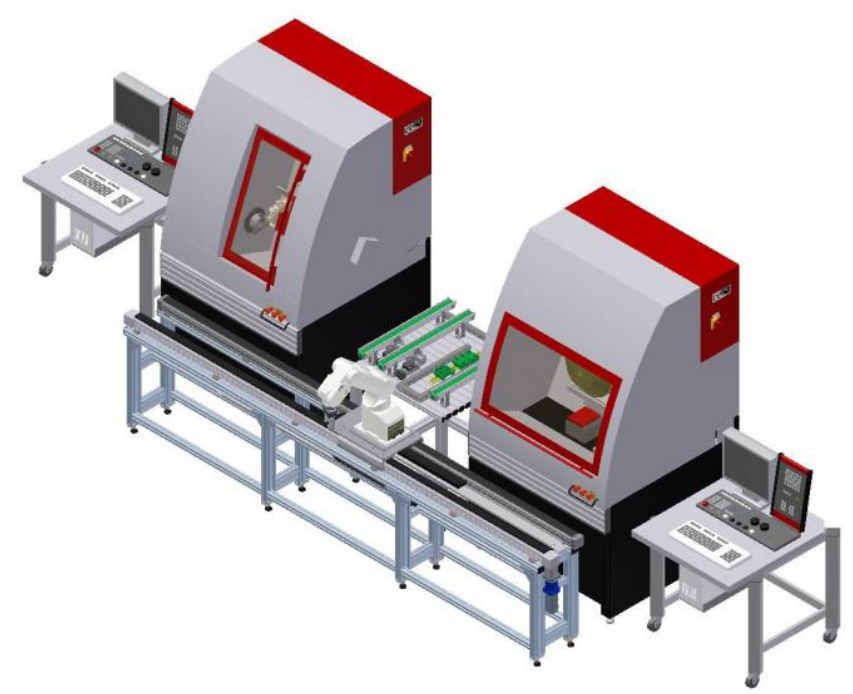

Fig. 1. Automated manufacturing micro FMS with two machine tools and robot manipulator

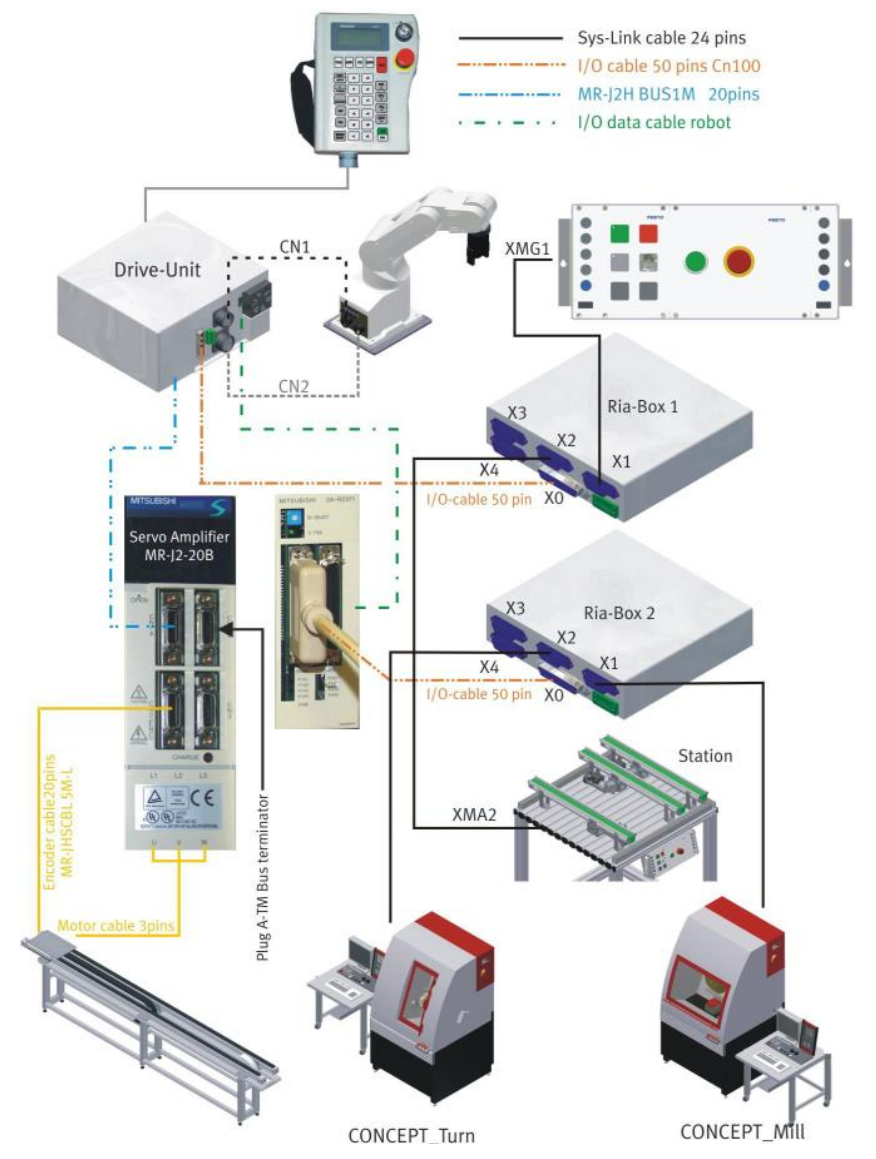

Fig. 2. Representation and Description main components of FMS

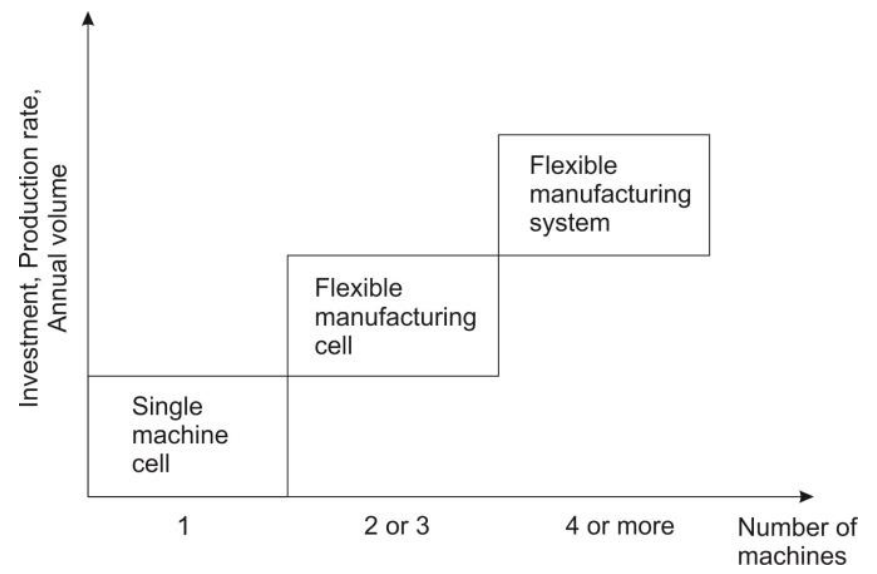

Fig. 3. Features of the three categories of flexible cells and systems

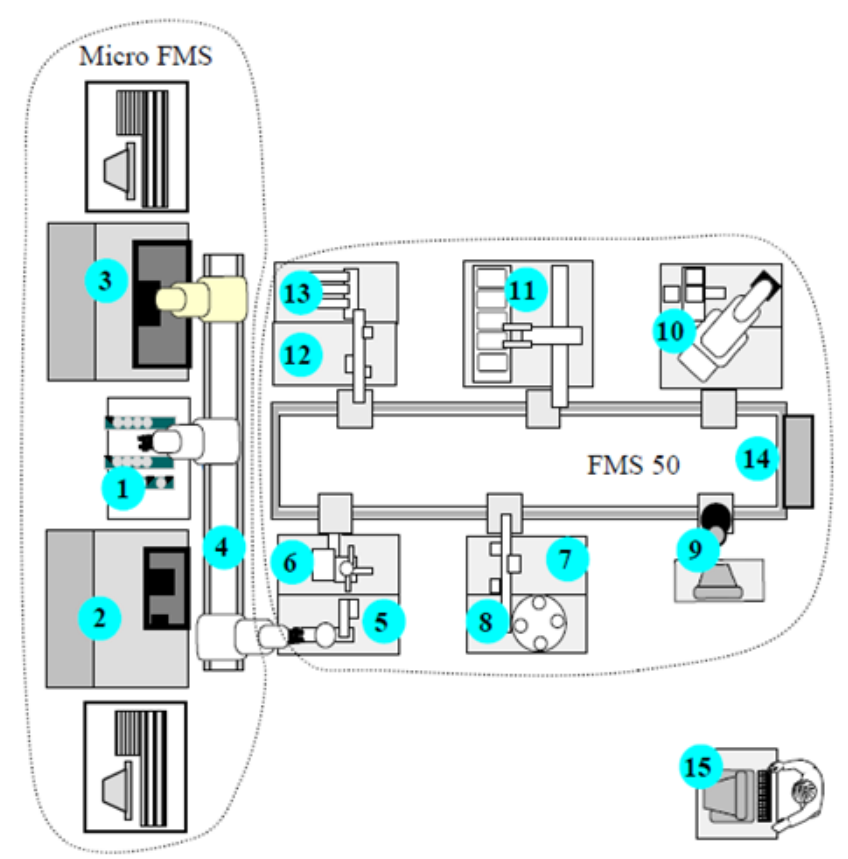

Fig. 4. Plan view of a fourteen-stations a micro flexible manufacturing system

TABLE I. MULTI FMS'S ELEMENTS DESCRIPTION

\begin{tabular}{|c|l|}
\hline 1 & Buffering conveyors \\
\hline 2 & CNC lathing machine Turn $\mathbf{1 0 5}$ \\
\hline 3 & CNC milling machine Mill 105 \\
\hline 4 & 5-axes robot with additional slide \\
\hline 5 & Distribution station AS-i \\
\hline 6 & Testing station \\
\hline 7 & Handling station \\
\hline 8 & Processing station \\
\hline 9 & Vision camera system \\
\hline 10 & Assembling station \\
\hline 11 & AS/RS 20 station \\
\hline 12 & Handling station II \\
\hline 13 & Sorting station Profibus-DP \\
\hline 14 & Conveyor system \\
\hline 15 & SCADA workstation \\
\hline
\end{tabular}




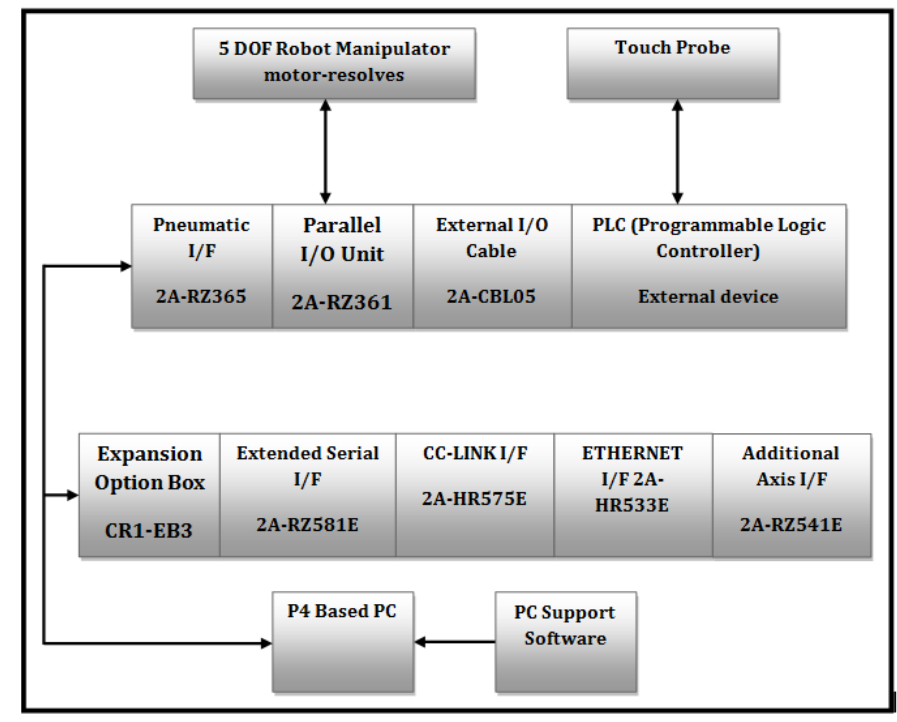

Fig. 5. Controller hardware structure of material handling robot manipulator
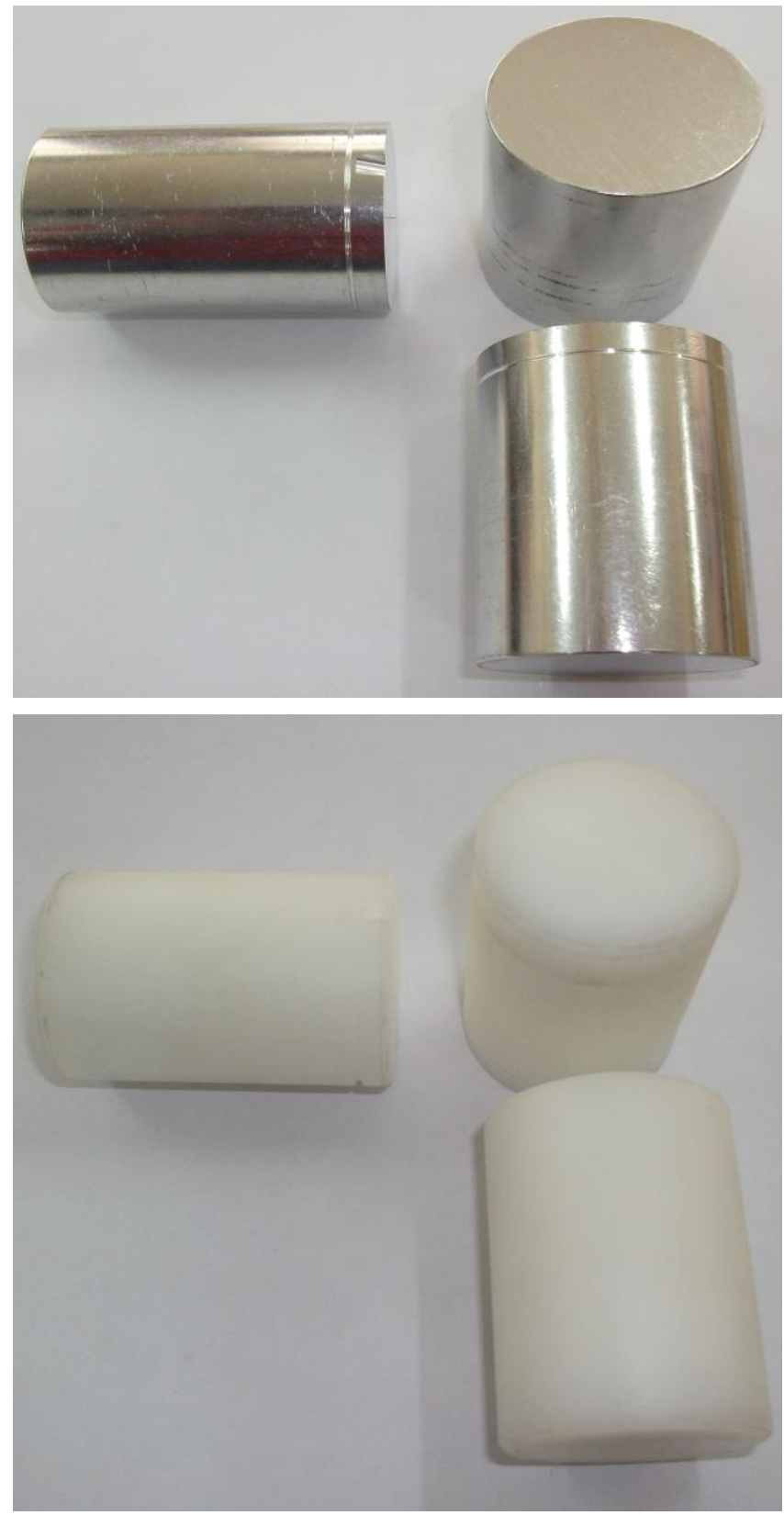

Fig. 6. View of metal and plastic materails

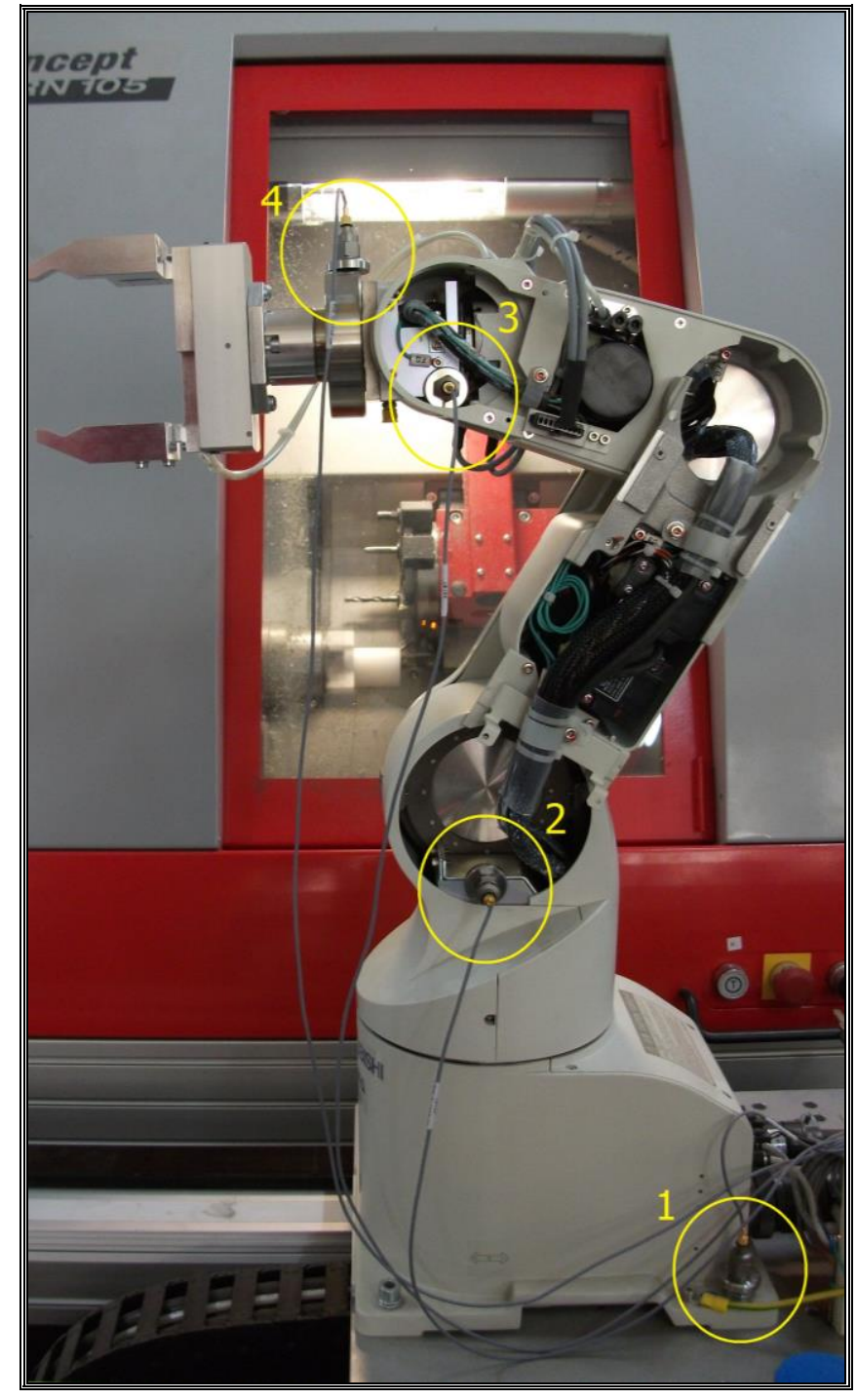

Fig. 7. View of experimental material handling robot manipulator's measuring points 
TABLE II. DYNAMICS AND KINEMATICS PARAMETERS OF ROBOT MANIPULATOR

\begin{tabular}{|c|c|c|c|}
\hline \multicolumn{2}{|c|}{ ITEM } & UNIT & SPECIFICATIONS \\
\hline \multicolumn{2}{|c|}{ Degree of freedom } & & 5 \\
\hline \multicolumn{2}{|c|}{ Installation posture } & & On floor \\
\hline \multicolumn{2}{|c|}{ Structure } & & Vertical, multiple-joint type \\
\hline \multicolumn{2}{|c|}{ Drive system } & & $A C$ servo motor \\
\hline \multicolumn{2}{|c|}{ Position detection method } & & Absolute encoder \\
\hline \multirow{5}{*}{ Arm length } & Shoulder shift & \multirow{5}{*}{$m m$} & 0 \\
\hline & Upper arm & & 250 \\
\hline & Fore arm & & 160 \\
\hline & Elbow shift & & 0 \\
\hline & Wrist length & & 72 \\
\hline \multirow{5}{*}{$\begin{array}{c}\text { operating } \\
\text { range }\end{array}$} & $J 1$ & \multirow{5}{*}{ Degree } & $300(-150$ to +150$)$ \\
\hline & $J 2$ & & $180(-60$ to +120$)$ \\
\hline & $J 3$ & & $230(-110$ to +120$)$ \\
\hline & $J 5$ & & $180(-90$ to +90$)$ \\
\hline & J6 & & $400(-200$ to +200$)$ \\
\hline \multirow{5}{*}{$\begin{array}{c}\text { Speed of } \\
\text { motion }\end{array}$} & $J 1$ & \multirow{5}{*}{ Degree/s } & 180 \\
\hline & $J 2$ & & 90 \\
\hline & $J 3$ & & 135 \\
\hline & $J 5$ & & 180 \\
\hline & J6 & & 210 \\
\hline \multirow{5}{*}{$\begin{array}{c}\text { Speed of } \\
\text { motion }\end{array}$} & $J 1$ & \multirow{5}{*}{ Degree/s } & 180 \\
\hline & $J^{2}$ & & 90 \\
\hline & $J 3$ & & 135 \\
\hline & $J 5$ & & 180 \\
\hline & J6 & & 210 \\
\hline \multicolumn{2}{|c|}{ Maximum resultant velocity } & $\mathrm{mm} / \mathrm{s}$ & 2100 \\
\hline \multirow{2}{*}{ Load } & Maximum & \multirow{2}{*}{$\mathrm{kg}$} & 2 \\
\hline & Rating & & 1.5 \\
\hline \multicolumn{2}{|c|}{ Pose repeatability } & $m m$ & \pm 0.02 \\
\hline \multicolumn{2}{|c|}{ Ambient temperature } & ${ }^{\circ} \mathrm{C}$ & 0 to 40 \\
\hline \multicolumn{2}{|c|}{ Mass } & $\mathrm{kg}$ & 17 \\
\hline \multirow{2}{*}{$\begin{array}{c}\text { Allowable } \\
\text { moment load }\end{array}$} & $J_{5}$ & \multirow{2}{*}{$\mathrm{Nm}$} & 2.16 \\
\hline & $J_{6}$ & & 1.10 \\
\hline \multirow{2}{*}{$\begin{array}{c}\text { Allowable } \\
\text { inertia }\end{array}$} & $J_{5}$ & \multirow{2}{*}{$\mathrm{Kgm}^{2}$} & $3.24 \times 10^{-2}$ \\
\hline & $J_{6}$ & & $8.43 \times 10^{-3}$ \\
\hline \multicolumn{2}{|c|}{ Arm reachable radius } & $m m$ & 410 \\
\hline \multicolumn{2}{|c|}{ Tool wiring } & & $\begin{array}{l}\text { Four input signals (Hand section) } \\
\text { Four output signals (Base section) } \\
\text { Motorized hand output (Hand sect.) }\end{array}$ \\
\hline \multicolumn{2}{|c|}{ Tool pneumatic pipes } & & $64 \times 3$ \\
\hline Supply & ressure & $M P a$ & $0.5 \pm 10 \%$ \\
\hline
\end{tabular}
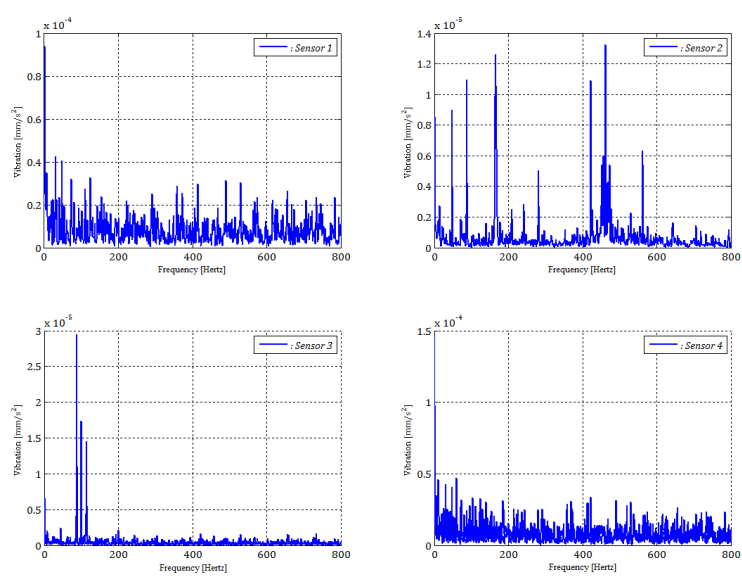

Fig. 8. Vibration variations on robot manipultor handling and feeding metal material for four joints at the minimum speed
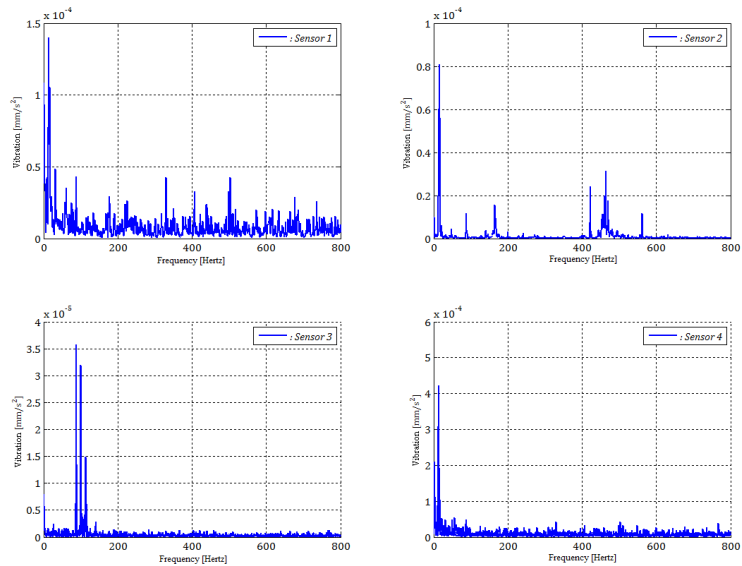

Fig. 9. Vibration variations on robot manipultor handling and feeding plastic material for four joints at the minimum speed
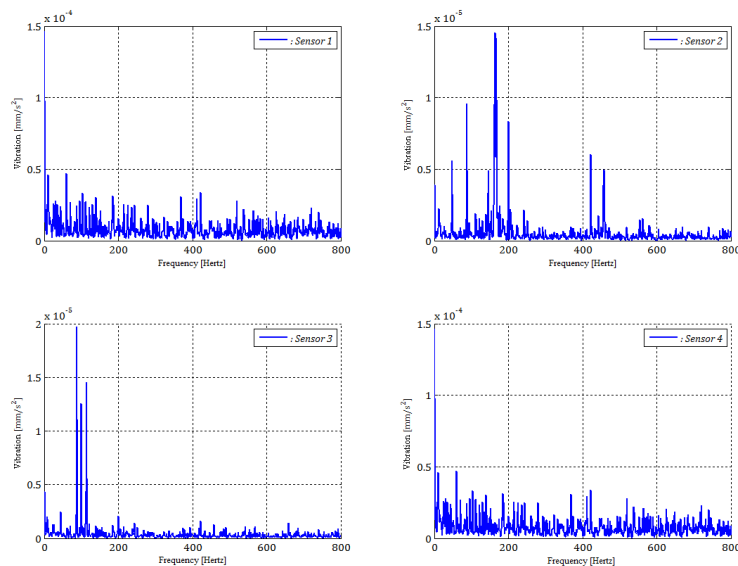

Fig. 10. Vibration variations on robot manipultor handling and feeding metal material for four joints at the maximum speed of $50 \%$ 

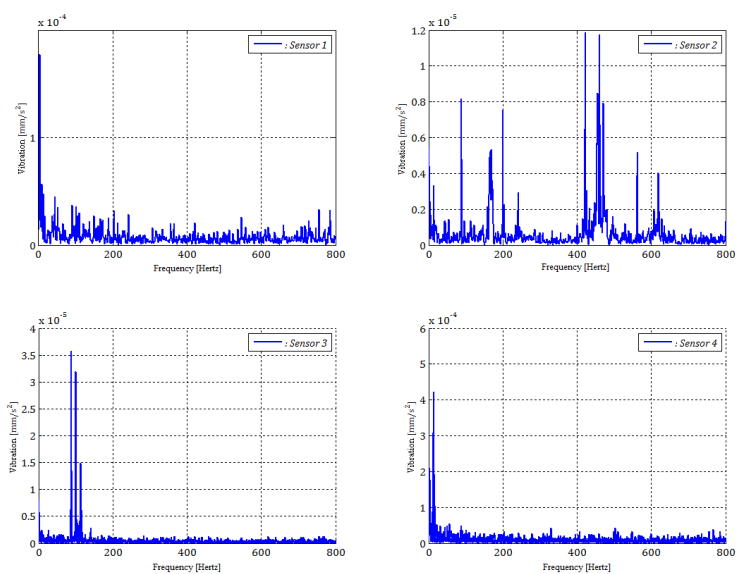

Fig. 11. Vibration variations on robot manipultor handling and feeding plastic material for four joints at the maximum speed of $50 \%$
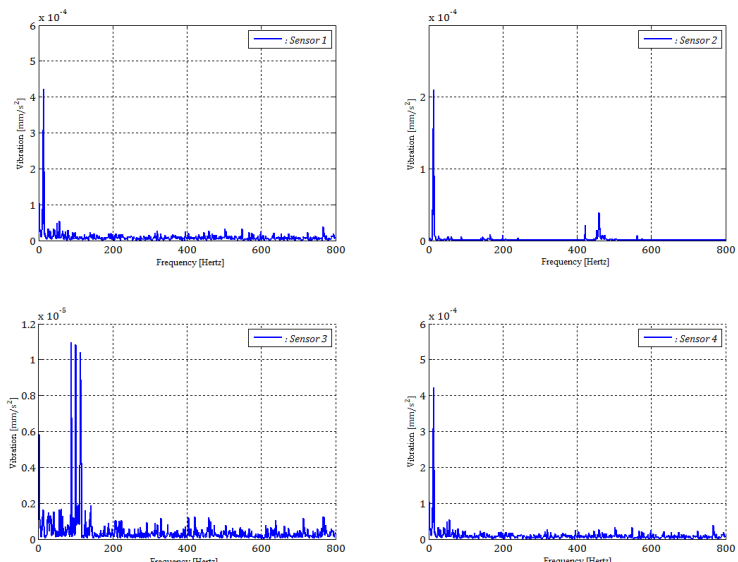

Fig. 12. Vibration variations on robot manipultor handling and feeding metal material for four joints at the maximum speed of $70 \%$
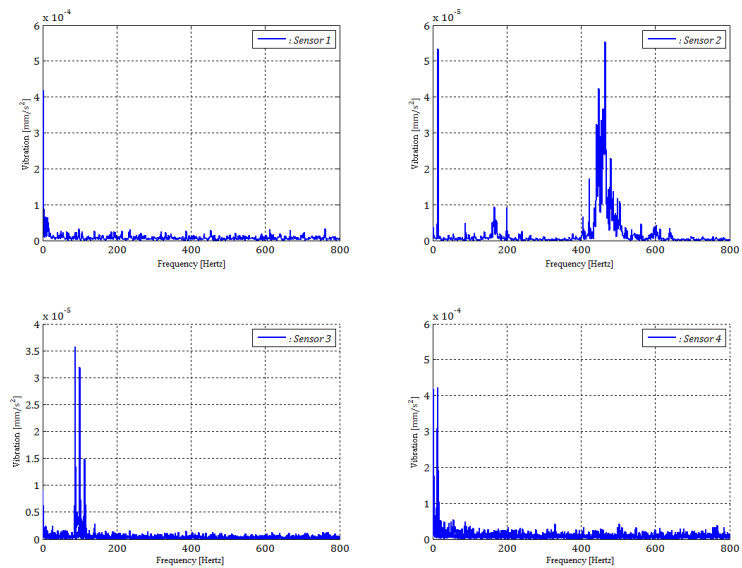

Fig. 13. Vibration variations on robot manipultor handling and feeding plastic material for four joints at the maximum speed of $70 \%$
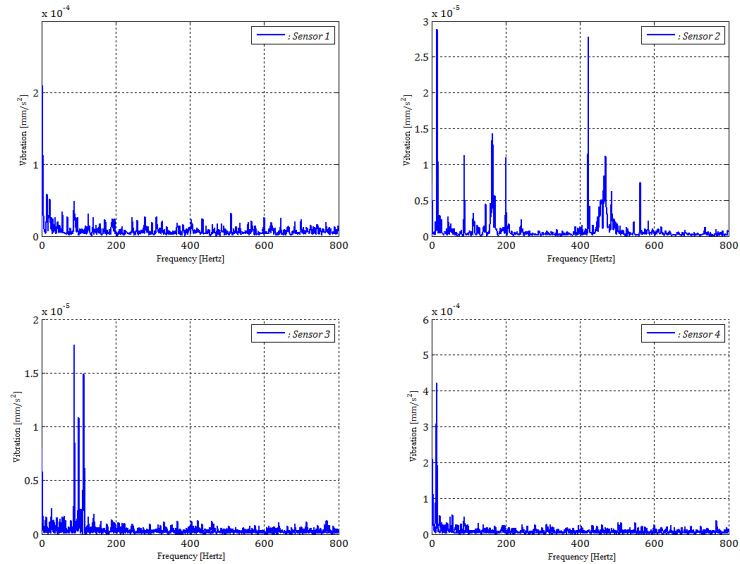

Fig. 14. Vibration variations on robot manipultor handling and feeding metal material for four joints at the maximum speed
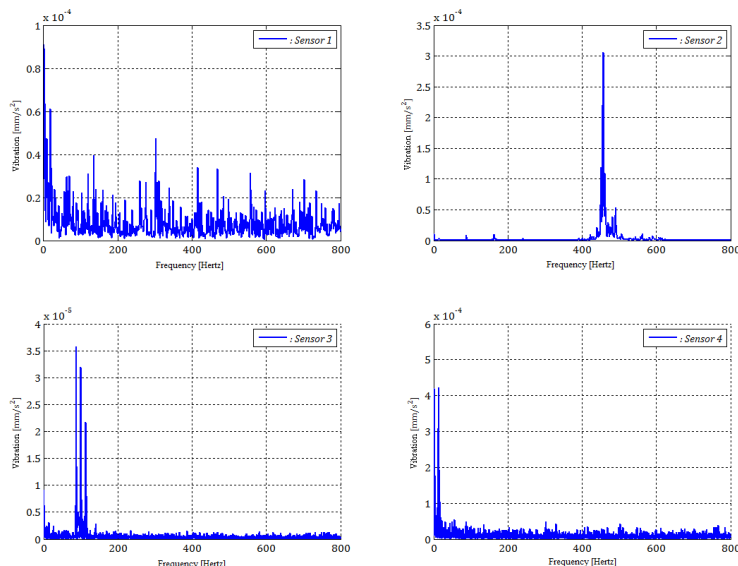

Fig. 15. Vibration variations on robot manipultor handling and feeding plastic material for four joints at the maximum speed

\section{CONCLUSION AND DISCUSSION}

In this experimental investigation, fault detection of a micro FMS based vibration analyisis for an 5 degrees of freedom (DOF) industrial material handling robot manipülatör has been implemented. Joint accelerations of robot manipülatör are considered as analysis and evaluation criteria. For this purpose, an experimental setup is used to collect the related values. The accelerations of material handling robot are analyzed during feeding polymid plastic and alimnium materials for micro FMS. The results obtained for the four running speeds show that the robot manipultor with $\% 70$ reduced speed a robust stability to analyze the accelerations of manipulator joints during a prescribed micro FMS process cycle.

The major advantage of $\% 70$ of maximum speed of robot manipulator's joints have been given response that drops off rapidly the peak of joint's accerations.

In the future studies, by using the proposed fault detection technique, fault isolation of material handling and feeding robot manipulator joints in considering with a larger number of degrees of freedom can be employed. Also, a kind of neural predictor can be adapted to the fault detection for the other types of robot manipulator. 


\section{REFERENCES}

[1] Abdulziz M. El-Tamimi, Mustufa H. Abidi, S. Hammad Mian, Javed Aalam. 2012. Analysis of performance measures of flexible manufacturing system. Journal of King Saud University - Engineering Sciences , 24, 115-129

[2] Abou-Ali, M. G. \& Shouman, M. A. 2004. Effect of Dynamic and Static Dispatching Strategies on Dynamically Planned and Unplanned FMS. Journal of Materials Processing Technology,148,132-138.

[3] Abou Gamilla, M., Motavalli, S., Nawara, G. \& Reyad, A. 2000. An Integrated Planning System for Tool Management and Part Scheduling in FMS. 4th International Conference on Engineering Design and Automation. Orlando, Florida, USA.

[4] Azimi, P., Haleh, H. \& Alidoost, M. 2010. The selection of the best control rule for a multiple-load AGV system using simulation and fuzzy MADM in a flexible manufacturing system. Model. Simul. Eng., 2010, $1-11$.

[5] Basnet, C. \& Mize, J. H. 1994. Scheduling and Control of Flexible Manufacturing Systems: A Critical Review. International Journal of Computer Integrated Manufacturing, 7, 340-355.

[6] Bruce, W. \& Albert, L. 1999. A Strategic Investment Model for Phased Implementation of Flexible Manufacturing Systems. International Transaction in Operational Research, 6, 331-344.

[7] Chan, F. \& Swarnkar, R. 2006. Ant Colony Optimization Approach to a Fuzzy Goal Programming Model For A Machine Tool Selection And Operation Allocation Problem In An FMS. Robotics and ComputerIntegrated Manufacturing, 22, 353-362.

[8] Chan, F. T. S. \& Chan, H. K. 2004. A Comprehensive Survey and Future Trend of Simulation Study on FMS

[9] Scheduling. Journal of Intelligent Manufacturing, 15, 87-102.

[10] Chan, F. T. S., Chan, H. K. \& Lau, H. C. W. 2002. The State of the Art in Simulation Study on FMS Scheduling: A Comprehensive Survey. The International Journal of Advanced Manufacturing Technology, 19,

[11] 830-849.

[12] Chan, F. T. S., Rajat, B. \& Wadhwa, S. 2007. Taguchi's Method Analysis of an FMS Under Review-PeriodBased Operational Controls: Identification of Control Periodicity. Systems, Man and Cybernetics, Part A: Systems and Humans, IEEE Transactions on, 37, 212-225.

[13] Chen, F. F. \& Adam, E. E., JR. 1991. The impact of flexible manufacturing systems on productivity and quality. Engineering Management, IEEE Transactions on, 38, 33-45.

[14] Deveorshak, C. 2012. Plant Pest Risk Analysis: Concepts and Applications, UK, CAB International.

[15] Ecker, K. \& Gupta, J. 2005. Scheduling Tasks on a Flexible Manufacturing Machine to Minimize Tool Change Delays. European Journal of Operational Research, 164, 627-638.

[16] Hamid, U. 2010. Petri Net versus Queuing Theory for Evaluation of Flexible Manufacturing System. Advances in Production Engineering and Management, 5, 93-100.

[17] Géza, H. Csaba, S \& Hideki, H. 2014. Application of reconfigurable hardware technology in the development and implementation of building automation systems, Environmental Engineering and Managment Journal.

[18] Géza, H. Csaba, S \&; Chindris, V. 2010. Artificial Immune System Implementation upon Embryonic Machine for Hardware Fault-tolerant Industrial Control Applications. Journal of Computer Science and Technology.

[19] Hwang, H. \& Kim, S. H. 1998. Development of dipatching rules for automated guided vehicle systems. Journal of Manufacturing Systems, $17,137-143$

[20] Joseph, O. A. \& Sridharan, R. Effect of Part Launching Decisions on the Performance of a Flexible Manufacturing System: A Simulation Study. The 2008 IEEE Industrial Engineering and Engineering Management, 2008. 1744-1748.

[21] Joseph, O. A. \& Sridharan, R. 2011a. Effects of routing flexibility, sequencing flexibility and scheduling decision rules on the performance of a flexible manufacturing system. International Journal Of Advanced Manufacturing Technology, 56, 291 - 306.
[22] Joseph, O. A. \& Sridharan, R. 2011b. Simulation-based metamodels for the analysis of dynamic due-date assignment in a flexible manufacturing system. International Journal of Applied Management Science, 3, 341 367.

[23] Karsak, E. Fuzzy MCDM Procedure for Evaluating Flexible Manufacturing System Alternatives. The 2000 IEEE Conference, Engineering Management Society, 2000. 93-98.3.

[24] Kumar, N. S. \& Sridharan, R. 2011. Simulation-based Comparative Analysis of the Performance of a lexible Manufacturing System Operating under Part Movement Policy and Tool Movement Policy. International Journal of Industrial and Systems Engineering, 9, 388-411.

[25] Leondes, C. T. 2003. Computer Aided and Integrated Manufacturing Systems World Scientific Publishing Co.Pte. Ltd.

[26] Mclean, C. and Kibira, D.(2002). Virtual Reality Simulation of a Mechanical Assembly Production Line. Proceeding of the 2002 Winter Simulation Conference. 1130-1137.

[27] Montgomery, D. C. 2006. Design and Analysis of experiments, 5th Edition, Wiley India Pvt. Limited. National Research Council. 1988. Flexible Machining in an Integrated System. Design and Analysis of Integrated Manufacturing Systems, Washington, DC, The National Academies Press.

[28] Prakash, A. \& Chen, M. Performance Evaluation of Flexible Manufacturing Systems using Factorial Design Techniques. WESCANEX 93. 'Communications, Computers and Power in the Modern Environment.' Conference Proceedings., IEEE, 1993 1993. $407-$ 415.

[29] Pramod, M. \& Garg, S. 2006. Analysis of Flexibility Requirements under Uncertain Environments. Journal of Modelling in Management, 1,196-214.

[30] Rao, H. A. \& Gu, P. 1997. Design Methodology and Integrated Approach for Design of Manufacturing Systems. Integrated Manufacturing Systems, 8, 159-172.

[31] Saygın, C., Chen, F. \& Singh, J. 2001. Real-Time Manipulation of Alternative Routings in Flexible Manufacturing Systems: A Simulation Study. International Journal of Advanced Manufacturing Technology, 18, 755-763.

[32] Seidmann, A. 1993. Performance Management Issues in Flexible Manufacturing Systems: An Analytic Perspective. In: Sarin, R. `ed.) Perspectives in Operations Management. Springer US.

[33] Shafiq, S. I., Fahheem, M. \& Ali, M. 2010. Effect of Scheduling and Manufacturing Flexibility on the Performance of FMS. Global Journal of Flexible Systems Management, 11, 21 - 38.

[34] Shang, J. S. 1995. Robust Design and Optimization of Materia Handling in an FMS. International Journal of Production Research, 33, 2437-2454.

[35] Shivanand, H. K., Benal, M. M. \& Koti, V. 2006. Flexible Manufacturing System, New Delhi, New Age International (P) Ltd

[36] Singholi, A., Chhabra, D. \& ALI, M. 2010. Towards Improving the Performance of Flexible Manufacturing

[37] System: A Case Study. Journal of Industrial Engineering and Management, 3, 87 .

[38] Solot, P. \& Vliet, M. 1994. Analytical models for FMS design optimization: A survey. International Journal of Flexible Manufacturing Systems, 6, 209-233.

[39] Su, C. Configure and Parameters' Optimization for Sheet Metal Flexible Manufacturing System Based on Simulation. Automation and Logistics, 2007 IEEE International Conference on, 18-21 Aug. 2007, 3074-3077.

[40] Yifei, T., Junruo, C., Meihong, L., Xianxi, L. \& Yali, F. An Estimate and Simulation Approach to Determining the Automated Guided Vehicle Fleet Size in FMS. Computer Science and Information Technology (ICCSIT), 2010 3rd IEEE International Conference on, 9-11 July 2010. 432-435.

[41] Yildirim, S. 2008. Design of a proposed neural network control system for trajectory controlling of walking robots, Simulation Modelling Practice and Theory, 16, 368-378. 